\title{
PERUBAHAN PAON PADA RUMAH TRADISIONAL DI DESA BATUAN SUKAWATI
}

\author{
Putu Arya Wiastina Putra \\ Program Studi Arsitektur, Fakultas Teknik, Universitas Dwijendra \\ (aryawiastina@gmail.com)
}

\begin{abstract}
Anak Agung Ayu Sri Ratih Yulianasari, S.T., M.Ars.
\end{abstract}
Program Studi Arsitektur, Fakultas Teknik, Universitas Dwijendra

(agungratih@undwi.ac.id)

\begin{abstract}
ABSTRAK
Bali merupakan daerah yang terkenal dengan sejuta keindahan dan pesonanya. Keindahan alam, keramah tamahan penduduk serta Adat dan Budaya yang adi luhur menjadi aset yang sangat berharga bagi Bali khususnya dan Indonesia pada umumnya. Dari semua keindahan dan keunikan itu satu hal yang penting untuk diperhatikan adalah tentang Arsitektur Tradisional Bali yang berlandaskan akan budaya dan bernafaskan Agama Hindu.

Dalam studi tentang pembangunan bangunan Bali, khususnya Paon atau dapur ini dilakukan guna memahami lebih mendalam lagi sebagian dari ilmu pengetahuan arsitektur tradisional Bali yang mendekati kebenaran, arah pembangunan, serta nilai luhur yang tinggi dari warisan nenek moyang kita menjadi kukuh dan kuat, Untuk itu perlu dilakukan penelitian perubahan apa saja yang terjadi pada bangunan Paon di desa Batuan Sukawati. Sehingga dapat diungkapkan untuk menambah perbendaharaan kebudayaan bangsa sebagai suatu bahan informasi dan gambaran yang menyeluruh bagi masyarakat Bali khususnya. Adapun rumusan masalah yang diangkat yakni: Bagaimana perubahan Paon pada rumah tradisional di Desa Batuan Sukawati.

Penelitian ini menggunakan pendekatan induktif untuk konsep tersebut dirumuskan dari beberapa unsur diantaranya: Observasi lapangan dan wawancara dengan ahli/pakar. Dapat disimpulkan: Bentuk bangunan Paon tidak mengalami perubahan namun dasi segi material saja yang mengalami perubahan seiring perkembangan zaman seperti penggunaan bahan penutup atap yang semualnya menggunakan alang-alang menjadi genteng.
\end{abstract}

Kata Kunci: Bali - Paon - Rumah Tradisional.

\section{ABSTRACT}

Bali is an area famous for its million beauty and charm. The beauty of nature, the hospitality of the people and the sublime Customs and Culture are very valuable assets for Bali in particular and Indonesia in general. Of all the beauty and uniqueness, one thing that is important to note is about Balinese Traditional Architecture which is based on culture and breathes Hinduism.

In the study of the construction of Balinese buildings, especially Paon or kitchens, this was carried out to understand more deeply some of the traditional Balinese architectural knowledge that approaches the truth, the direction of development, and the high noble values of our ancestral heritage to be strong and strong. a research was conducted on what changes occurred in the Paon building in the village of Batuan, Sukawati. So that it can be expressed to add to the nation's cultural treasury as a material for information and a comprehensive picture for the Balinese people in particular. The formulation of the problem raised is: How does Paon change in a traditional house in Batuan Village, Sukawati.

This study uses an inductive approach to the concept formulated from several elements including: field observations and interviews with experts / experts. It can be concluded: The shape of the Paon building has not changed, but only in terms of materials have changed over time, such as the use of roof covering materials, which all use reeds to become tiles.

Keywords: Bali - Paon - Traditional Houses. 


\section{PENDAHULUAN}

Paon adalah untuk tempat memasak dan juga dapat digunakan sebagai tempat tidur. Fasilitas di dalam bangunan Paon ini adalah 1 buah bale-bale yang terletak di bagian dalam dan tungku tradisional sebagai tempat untuk memasak. Bangunan Paon adalah rumah tinggal yang memakai bebaturan dengan lantai yang lebih rendah dari bale Dauh. Dapur atau yang biasanya disebut Paon dalam bahasa bali, berasal dari bahasa Jawa yaitu Pawon (dapur) merupakan bagunan adat bali yang letaknya disisi selatan, yang umumnya berfungsi untuk memasak pada zaman dahulu dan juga masih ada digunakan sampai sekarang. Selain itu dalam kehidupan beragama di Bali, dapur merupakan stana (istana) Dewa Brahma.

Dalam kepercayaan di Bali Dewa Brahma dipercayai sebagai dewanya dapur, penguasa dan pelindung arah selatan, bersenjatakan Gada, berwahana Angsa, memiliki Sakti Dewi Saraswati, dan atribut serba merah. Disamping itu dapur juga erat kaitannya dengan Dewa Agni terutama pada tungku dapur (cangkem paon), yang memiliki sifat sarwa daksa, yang artinya membakar apapun yang berada disekelilingnya.

Disanalah pentingnya makna dan fungsi dapur / paon bali, kita sebagai masyarakat bali harus melestarikan tradisi dan budaya bali yang diturunkan oleh leluhur kita. Jadi jangan pernah beranggapan bahwa perkataan orang tua itu tidak benar atau hanya mitos. Karena kepercayaan orang bali kepada leluhur sangat luar biasa jadi jaganlah sekali menentang perkataan orang tua atau bisa berakibat fatal pada diri kita sendiri.

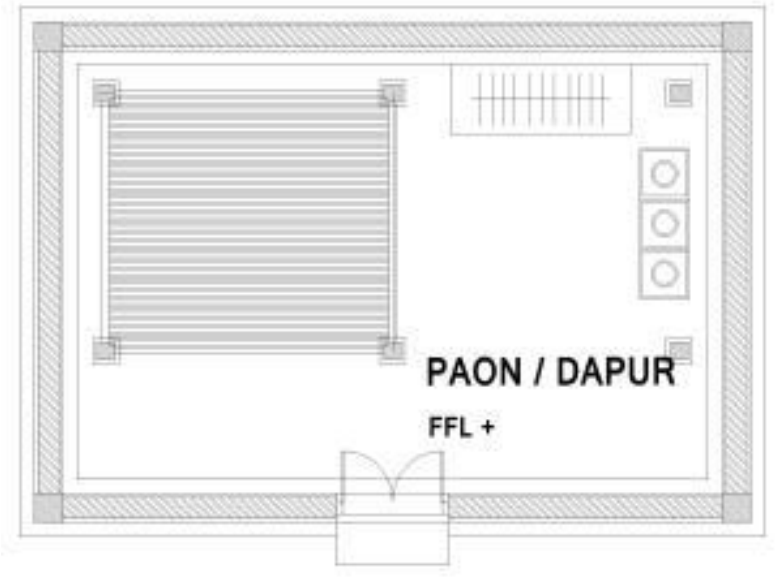

Gambar 1. Denah Bangunan Paon

Sumber: Analisa Pribadi, 2019

Dapur / paon memiliki fungsi yang sangat penting yang dipercayai oleh masyarakat bali adalah untuk menetralisir energi negative atau bhuta kala yang mengikuti sampai ke rumah. Jadi hendaknya ketika datang dari bepergian, janganlah langsung masuk ke dalam kamar ataupun ruang utama di rumah. Hendaknya mauk dapur terlebih dahulu. Disamping itu, begitu pentingnya fungsi dapur dipandang dari sisi stana dewatanya, dapur juga sebagai tempat orang bali selalu nunas penglukatan. Nunas penglukatan didapur tidak sembarangan, biasanya nunas penglukatan dilakukan ketika baru datang dari tempat melayat atau biasanya disebut setelah pulang dari (ngayang banjar) dari tempat orang meninggal. Penglukatan dilakukan cara mengambil air yang 
ada didapur, kemudian dilempar keatas genteng dapur sampai air turun dari genteng dan basuh kepala dan muka dari air tersebut.

Dibangunnya bangunan Paon adalah sebagai bangunan pokok yang di gunakan sebagai tempat bertahan hidup untuk mengolah bahan untuk sesajen dan makanan. utama dalam mengumpulkan sesaji yang akan dihaturkan kepada Ida Sang Hyang Widhi Wasa. Adapun rumusan masalah yang diangkat yakni: Bagaimana perubahan Paon pada rumah tradisional di Desa Batuan Sukawati. Tujian dari penelitian ini adalah untuk mengetahui perubahan apa saja yang terjadi pada bangunan Paon di Desa Batuan Sukawati.

Bangunan Paon yang terletak di Desa Batuan Sukawati memiliki keunikan tersendiri jika dibandingkan dengan Bangunan tradisional lain. Dan keunikan-keunikan ini merupakan ciri khas bangunan Paon. Adapun keunikan-keunikan itu dapat kita lihat pada bagian kepala dan badannya, diantaranya adalah:

a. Pada bagian kepala terdapat tempat penyimpanan kayu bakar.

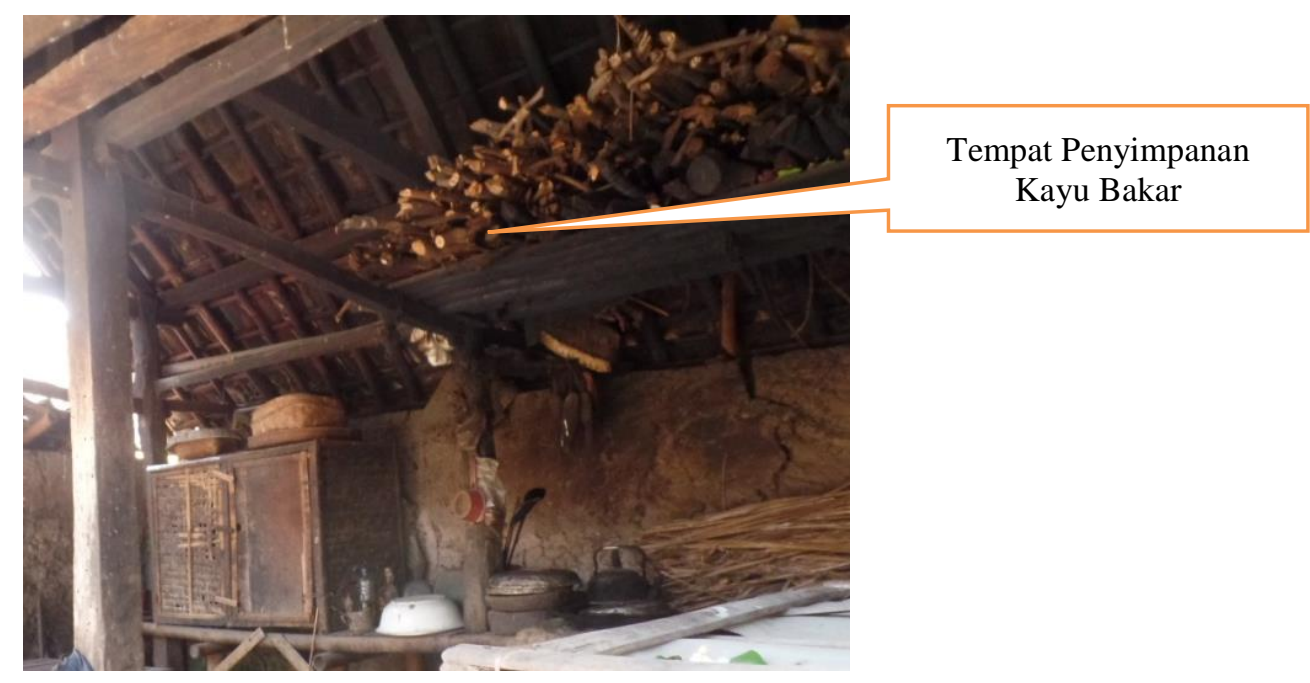

Gambar 2. Interior Bangunan Paon

Sumber: Observasi Lapangan, 2019

b. Bagian badan merupakan ciri khas dari bangunan Paon yang berfungsi sebagai tempat memasak, menyimpang air minum dan tempat meracik bahan makanan. 


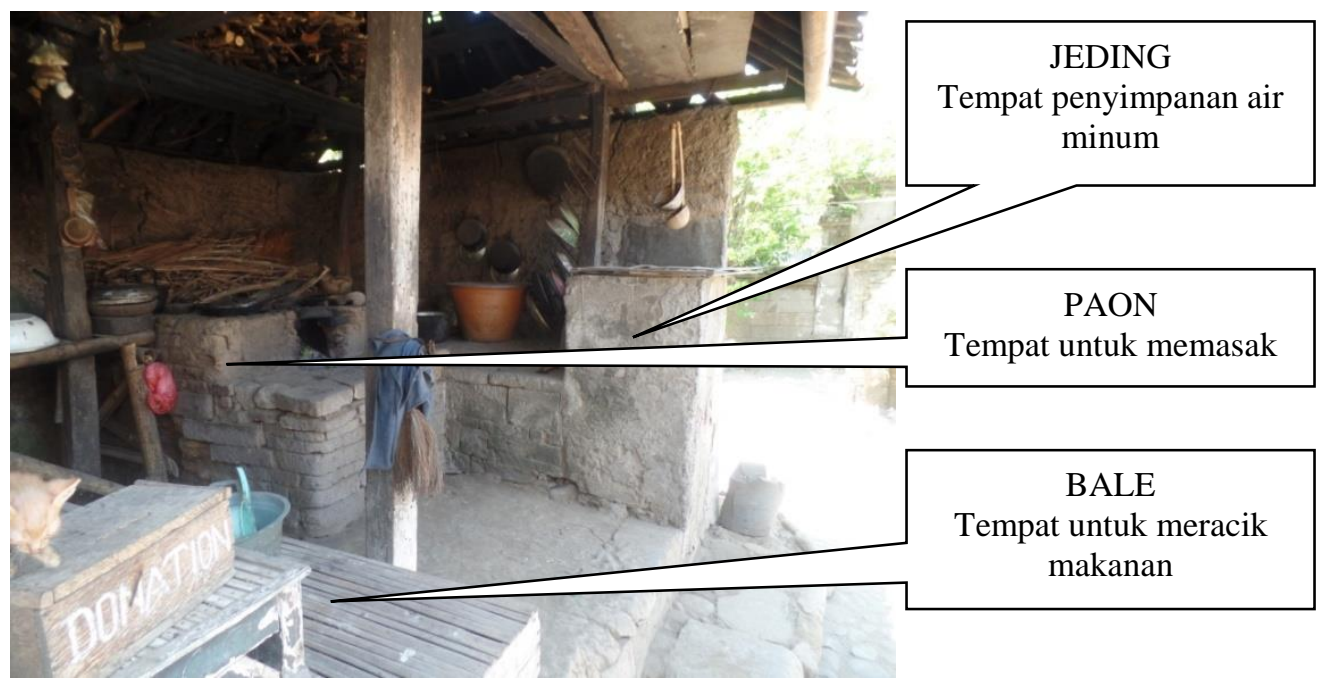

Gambar 3. Interior Bangunan Paon

Sumber: Observasi Lapangan, 2019

\section{METODE}

Dalam pengumpulan data-data yang dapat mendukung penulisan ini, menggunakan beberapa teknik yaitu:

a. Studi Literatur yaitu dengan memilih data-data literatur yang ada kaitannya dengan permasalahan yang ada.

b. Observasi yaitu dengan cara mengadakan pengamatan langsung ke lapangan dengan mengambil beberapa sample yang nantinya dapat dipakai perbandingan di dalam perancangan.

c. Wawancara yaitu dengan melakukan wawacara langsung dengan orang yang berkompeten dan dapat dipercaya dalam permasalahan ini seperti Pedanda, Undagi, Tukang Banten dll.

\section{HASIL DAN PEMBAHASAN}

\section{A. Paon Pada Zaman Dahulu}

Adanya berbagai macam bangunan tradisional yang ada di Bali ini sesuai dengan konsep Tri Hita Karana yang diyakini oleh masyarakat Hindu di Bali. Konsep Tri Hita Karana ini merupakan konsep kehidupan dari masyarakat Bali didalam menjalani kehidupan sehari-hari untuk mencapai kehidupan yang selaras, serasi dan seimbang kepada semua mahluk yang hidup di dunia.(Acwin dwijendra, $2010: 02$ ).

Konsep Tri Hita Karana adalah:

1) Hubungan manusia dengan Tuhan

2) Hubungan manusia dengan manusia

3) Hubungan manusia dengan alam

Dengan menjalankan 3 konsep kehidupan ini, masyarakat Hindu di Bali percaya bahwa kehidupan akan menjadi lebih baik. Secara langsung pada penerapanya masyarakat bali mencoba menterjemahkan konsep Tri Hita Karana ini kedalam berbagai aspek kehidupan diantaranya di dalam suatu wilayah desa mempunyai 3 unsur pokok diantaranya. 
Seperti halnya bentuk-bentuk bangun tradisonal bali yang lain, Bangunan Paonmemakai konsep Triangga yaitu memiliki tiga bagian diantaranya:

1. Bagian kaki disebut dengan bataran yaitu, bataran yang terletak paling bawah, terbuat dari pasangan batu.

2. Bagian badan yaitu, bagian tengah Paon, Saka,Tembok, jendelapada Paon.

3. Bagian kepala yaitu, bagian paling atas dari bangunan Paon tepatnya diatas Lambang sampai pada atap Paon.

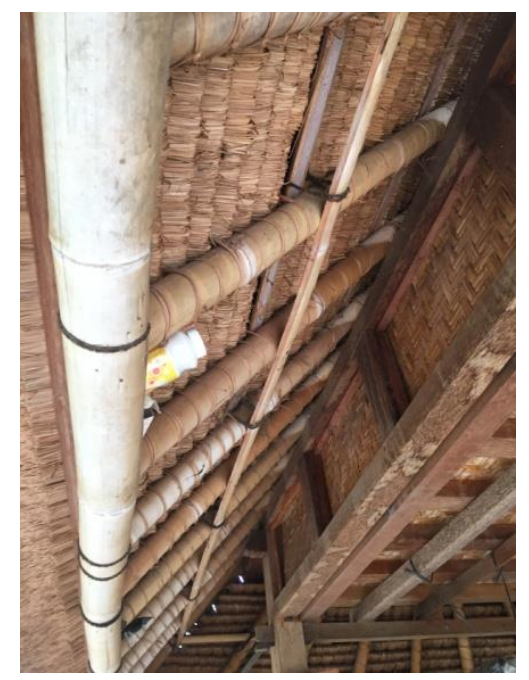

Gambar 4. Struktur Atap Bangunan Paon

Sumber: Observasi Lapangan, 2019

\section{B. Proses Perencanaan}

Di dalam pembangunan sebuah Bangunan Paon diperlukan tenaga-tenaga ahli seperti: tenaga pengarah upacara, pelaksana fisik, dan penata hiasan. Adapun tenaga dalam pelaksanaan fisiknya adalah : tenaga perencana, tenaga ahli.

1) Tenaga perencana

Didalam arsitektur tradisional Bali, undagi merupakan tenaga perencana yang bisa merancang suatu bangunan yang sesuai dengan aturan-aturan arsitektur tradisional Bali. Dalam hal ini Bangunan Bale agung merupakan suatu bangunan yang memakai aturanaturan arsitektur tradisional Bali, sehingga seorang undagi sangat diperlukan didalam proses perancangannya, mulai dari pembuatan gegulak sebagai satuan-satuan dimensi sampai pada pembuatan sukatnya.

2) Tenaga ahli

Tenaga ahli didalam proses mulai dari persiapan sampai pada tahap penyelesaian sangat dibutuhkan, misalnya didalam menentukan dewasa ayu, merancang, membangun dan melaspas pelinggih. Undagi yang seniman dan yang telah berada dalam tingkatan empu merupakan tenaga ahli yang seutuhnya, yang dapat menentukan dewasa ayu, perancangan ragam hias, pelaksanaan dan sampai pada upacaranya.

Berikut merupakan tenaga ahli dalam bidangnya :

1. Ahli menentukan hari baik ( dewasa ayu) disebut dengan ahli wariga.

2. Ahli yang menguasai weda-weda dalam pedoman pemujaan dan pedoman pujaastawa dikuasai oleh sulinggih dan pemangku.

3. Ahli dalam pengerjaan banten disebut dengan tukang banten. 
4. Undagi dalam pelaksanaan proses pembangunan dibantu oleh beberapa tukang ahli dalam bidang tertentu misalnya : tukang kayu, tukang mengatapi, tukang ukir, dan tenaga ahli lainnya.

\section{Proses Persiapan}

Dalam proses persiapan ada beberapa tahap yang harus di laksanakan yaitu:

a) Penentuan lokasi

Untuk mendirikan Bangunan Paon harus ditentukan dulu dimana posisi Bangunanpaon yang akan dibangun agar sesuai dengan ketentuan, jenis dan fungsi Bangunanpaon yang dalam arsitektur tradisional Bali proses ini disebut dengan nyukat dengan disertai upacara terlebih dahulu.

b) Menentukan / membuat gegulak.

Untuk menentukan gegulak, yang diambil adalah orang yang dituakan didalam suatu keluarga sebagai pangemongrumah/umah yang akan dibangun. Dalam pembuatan gegulak harus melalui upacara pembuatan gegulak terlebih dahulu.

c) Pengadaan bahan.

- Penggunaan bahan untuk dasar, bataran menggunakan batu alam yang diambil dari jenis batu alam yang ada pada daerah setempat

- Penggunaan bahan atap juga diambil dari bahan yang ada di daerah setempat seperti ijuk, dan alang-alang.

- Kayu sebagai bahan konstruksi rangka rongan dipilih kayu yang baik untuk dipakai pada bale agung, dan didalam proses penebangannya juga sesuai dengan aturan arsitektur tradisional Bali yang disertai dengan upacara penebangan terlebih dahulu.

d) Pengolahan bahan.

Setelah bahan-bahan didapatkan, bahan-bahan seperti kayu dan batu alam tadi diolah atau dibentuk menjadi bahan-bahan setengah jadi.

Dapur / Paon memiliki fungsi yang sangat penting yang dipercayai oleh masyarakat bali adalah untuk menetralisir energi negative atau bhuta kala yang mengikuti sampai ke rumah. Jadi hendaknya ketika datang dari bepergian, janganlah langsung masuk ke dalam kamar ataupun ruang utama di rumah. Hendaknya mauk dapur terlebih dahulu. Disamping itu, begitu pentingnya fungsi dapur dipandang dari sisi stana dewatanya, dapur juga sebagai tempat orang bali selalu nunas penglukatan. Nunas penglukatan didapur tidak sembarangan, biasanya nunas penglukatan dilakukan ketika baru datang dari tempat melayat atau biasanya disebut setelah pulang dari (ngayang banjar) dari tempat orang meninggal. Penglukatan dilakukan cara mengambil air yang ada didapur, kemudian dilempar keatas genteng dapur sampai air turun dari genteng dan basuh kepala dan muka dari air tersebut.

e) Penentuan lokasi

Untuk mendirikan Bangunan bale agung harus ditentukan dulu dimana posisi Bangunanpaon yang akan dibangun agar sesuai dengan ketentuan, jenis dan fungsi Bangunanpaon yang dalam arsitektur tradisional Bali proses ini disebut dengan nyukat dengan disertai upacara terlebih dahulu.

f) Menentukan / membuat gegulak. 
Untuk menentukan gegulak, yang diambil adalah orang yang dituakan didalam suatu keluarga sebagai pangemongrumah/umah yang akan dibangun. Dalam pembuatan gegulak harus melalui upacara pembuatan gegulak terlebih dahulu.

g) Pengadaan bahan.

- Penggunaan bahan untuk dasar, bataran menggunakan batu alam yang diambil dari jenis batu alam yang ada pada daerah setempat

- Penggunaan bahan atap juga diambil dari bahan yang ada di daerah setempat seperti ijuk, dan alang-alang.

- Kayu sebagai bahan konstruksi rangka rongan dipilih kayu yang baik untuk dipakai pada bale agung, dan didalam proses penebangannya juga sesuai dengan aturan arsitektur tradisional Bali yang disertai dengan upacara penebangan terlebih dahulu.

h) Pengolahan bahan.

Setelah bahan-bahan didapatkan, bahan-bahan seperti kayu dan batu alam tadi diolah atau dibentuk menjadi bahan-bahan setengah jadi.

\section{Proses Upacara}

Setelah bahan-bahan siap, lalu pada tahap selanjutnya adalah tahap pengerjaan, yang dimulai dari penngerjaan bagian bawah yaitu bataran sampai pada paon dan atapnya.

a. Pengerjaan bagian bawah atau bataran.

Pada bagian ini terdapat tepas hujan, bataran dan undag yang sudah diperhitungkan dimensinya pada saat perencanaan. Sebelum pemasangan tepas hujan dan bataran terlebih dahulu ada beberapa tahap proses dan upacara yang dilaksanakan mulai dari:

1) Proses dan upacara nyukat, yang bertujuan untuk menentukan posisi Paon yang akan dibangun.

2) Proses dan upacara ngeruak, yang bertujuan membersihkan lahan yang akan dibangun dan sekaligus membuat lubang pondasi sesuai dengan sukat

3) Proses dan upacara nasarin, yaitu peletakan batu pertama pada bangunan yang menggunakan sarana upacara.

4) Setelah proses dan upacara nasarin selesai baru dilanjutkan dengan proses pengerjaan babaturannya

b. Pengerjaan bagian badan/saka dan bale

Pada bagian badan ini merupakan pekerjaan konstruksi rangka kayu, dimulai dengan perakitan saka, sunduk, lambang, waton, slimar, pemade, kolong, dan iga-iga.

c. Pengerjaan bagian penutup atap

Pekerjaan setelah perakitan saka dan bale sampai ke rangka atap dilanjutkan dengan pemasangan penutup atap yaitu dengan memakai ijuk atau alang-alang.

\section{E. Tahap penyelesaian dan upacaranya}

Setelah Paon selesai secara keseluruhan, sebelum diupacarai, Paon tersebut terlebih dahulu dibersihkan secara fisik yang disebut dengan ngeresikin. Setelah paon benar-benar bersih, baru dibuatkan upacara terakhir yaitu memakuh dan melaspas. 


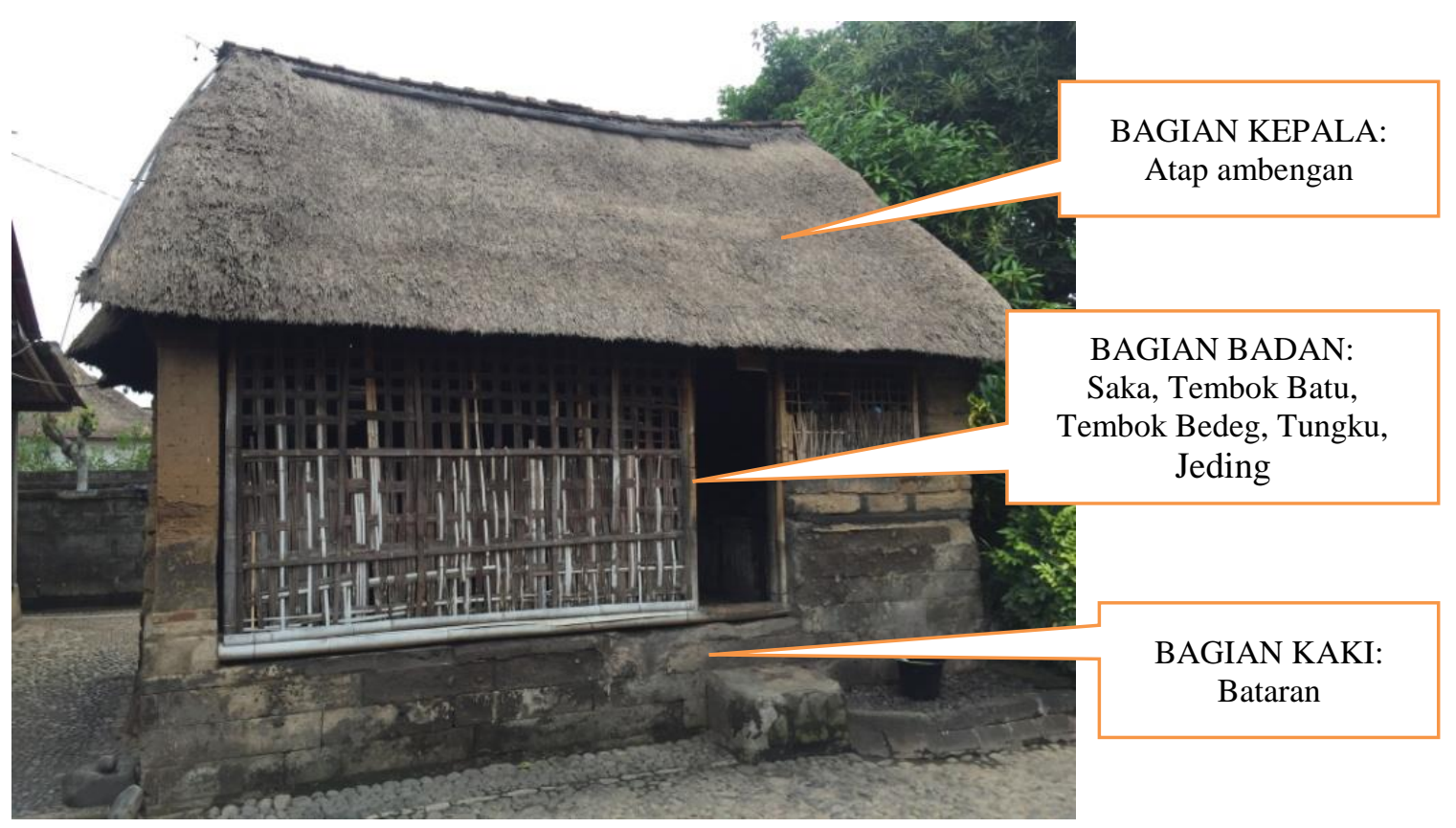

Gambar 5. Bangunan Paon Milik Agung Aji

Sumber: Observasi Lapangan, 2019

\section{F. Paon Pada Zaman Sekarang}

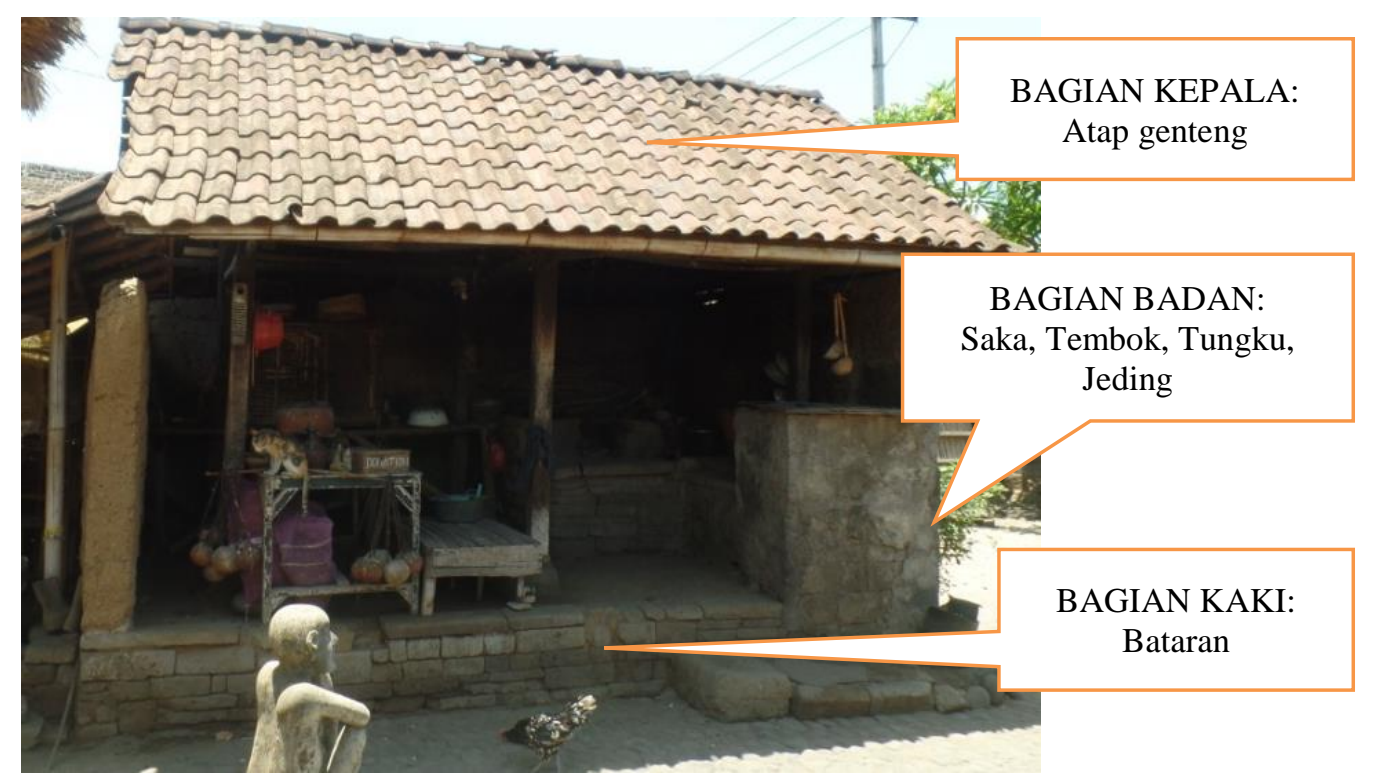

Gambar 6. Bangunan Paon Milik Made Tama

Sumber: Observasi Lapangan, 2019 


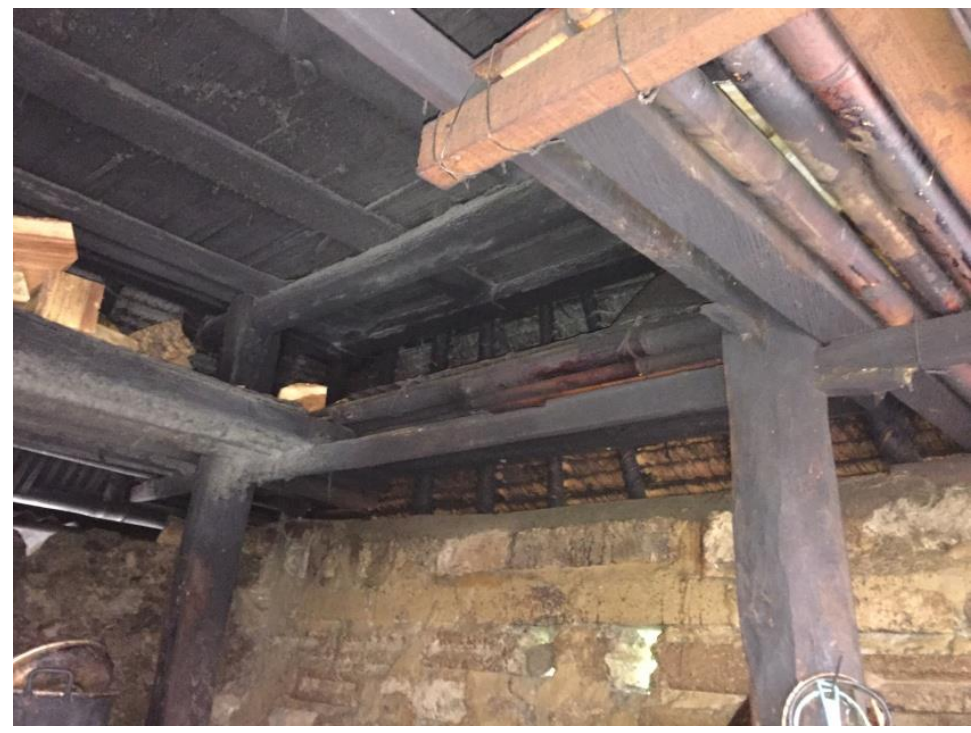

Gambar 7. Bangunan Paon Milik Made Tama

Sumber: Observasi Lapangan, 2019

Perubahan yang terjadi pada bangunan Paon bahan bangunan pada bangunan Paon disini dapat diuraikan menjadi beberapa bagian diantaranya:

a) Bagian bataran memakai bahan jenis batu-batuan yang keras yaitu:

1. Batu cadas

2. Batu kali

b) Bagian badan memakai bahan dari kayu tidak mempunyai penutup seperti bedeg (anyaman bambu)

c) Bagian atap, memakai bahan dari genteng dan struktur kayu

d) Bagian badan Paon bersifat terbuka merupakan ciri khas dari bangunan Paon yang berfungsi sebagai tempat memasak, menyimpang air minum dan tempat meracik bahan makanan.

e) Sistem struktur rangka

Sistem struktur rangka ini dipakai pada bagian badan sampai pada atapnya, dimana pada bagian bale sampai pada atapnya ini dibuat dari konstruksi kayu.

f) Sistem struktur massa

Sistem struktur massa ini dipakai pada bagian bataran,mulai dari dimana pada bagian bebaturan ini di bagian pinggirnya menggunakan pasangan batu cadas dan ditengahnya menggunakan penyegseg yang terbuat dari tanah.

Penyebab terjadinya perubahan tersebut diakibatkan karena untuk bahan atap dari alang-alang sudah sangat sulit untuk diperbaharui dan juga perlu perawatan khusus agar bahan tersebut tetap bauk kualitasnya maka beralihlah ke penggunaan penutup atap menggunakan genteng untuk lebih efisien karena sangat mudah dijumpai saat ini.

\section{Penutup}

\section{A. Simpulan}

Dari hasil data diatas dapat di simpulkan bahwa fungsi bangunan Paon tradisional bali yang terletak di desa Batuan Sukawati tetap memiliki fungsi dan bentuk yang sama, namun dapat dilihat dari tampilan bangunandan bahan mulai mengikuti perkembangan zaman agar 
lebih efisien. Perubahan tersebut dapat dilihat dari penggunaan penutup atap yang semulanya menggunakan alang-alang beralih menjadi penutup atap genteng.

\section{B. Saran}

Keberadaan paon harus tetap kita pertahankan dan lestarikan, karena Paon merupakan warisan dari pendahulu kita yang di dalamnya mengandung nilai-nilai filosofis dan sejarah yang harus selalu diingat hingga generasi orang-orang Hindu Bali selanjutnya.

\section{Daftar Pustaka}

Anom, Ida bagus, 2006. Ngwangun Parahyangan, Tabanan.

Acwin Dwijendra, 2010. Konsep Tri Hita Karana.

Bandesa K, Tonjaya, I Nym Gd, Riwayat Empu Kuturan, Penerbit Percetakan dan Toko Buku "Ria", Denpasar.

Gung Aji, 2019. Rumah yang berlokasi di Banjar Penida, Desa Batuan, Kecamatan Sukawati Kabupaten Gianyar.

Made Tama, 2019. Rumah yang berlokasi di Banjar Penida, Desa Batuan, Kecamatan Sukawati Kabupaten Gianyar.

Made Bandem, 2019. Ukuran-ukuran dan rancangan tentang arsitektur tradisional Bali.

Fakultas Teknik, Program Studi Arsitektur, Universitas Dwijendra Denpasar, Tugas-tugas SATB I, SATB II. 